\title{
Physician communication styles in initial consultations for hematological cancer
}

\section{Citation}

Chhabra, Karan R., Kathryn I. Pollak, Stephanie J. Lee, Anthony L. Back, Roberta E. Goldman, and James A. Tulsky. 2013. "Physician Communication Styles in Initial Consultations for Hematological Cancer." Patient Education and Counseling 93 (3) (December): 573-578. doi:10.1016/j.pec.2013.08.023.

\section{Published Version}

10.1016/j.pec.2013.08.023

\section{Permanent link}

http://nrs.harvard.edu/urn-3:HUL.InstRepos:34451367

\section{Terms of Use}

This article was downloaded from Harvard University's DASH repository, and is made available under the terms and conditions applicable to Open Access Policy Articles, as set forth at http:// nrs.harvard.edu/urn-3:HUL.InstRepos:dash.current.terms-of-use\#OAP

\section{Share Your Story}

The Harvard community has made this article openly available.

Please share how this access benefits you. Submit a story.

\section{Accessibility}


Published in final edited form as:

Patient Educ Couns. 2013 December ; 93(3): . doi:10.1016/j.pec.2013.08.023.

\title{
Physician Communication Styles in Initial Consultations for Hematological Cancer
}

\author{
Karan R. Chhabra, AB ${ }^{1}$, Kathryn I. Pollak, PhD $^{2,3}$, Stephanie J. Lee, MD, MPH ${ }^{4}$, Anthony L. \\ Back, MD ${ }^{4}$, Roberta E. Goldman, PhD $^{5,6}$, and James A. Tulsky, MD ${ }^{2,7,8}$ \\ ${ }^{1}$ Rutgers Robert Wood Johnson Medical School, New Brunswick, USA \\ ${ }^{2}$ Cancer Prevention, Detection and Control Research Program, Duke Cancer Institute, Durham, \\ USA \\ ${ }^{3}$ Department of Community and Family Medicine, Duke University Medical Center, Durham, USA \\ ${ }^{4}$ Fred Hutchinson Cancer Research Center, University of Washington, Seattle, USA \\ ${ }^{5}$ Department of Family Medicine, Alpert Medical School of Brown University, Providence, USA \\ ${ }^{6}$ Department of Social and Behavioral Sciences, Harvard School of Public Health, Boston, USA \\ ${ }^{7}$ Duke Palliative Care, Department of Medicine, Duke University Medical Center, Durham, USA \\ ${ }^{8}$ Health Services Research and Development Service, Durham VA Medical Center, Durham, USA
}

\section{Abstract}

Objective-To characterize practices in subspecialist physicians' communication styles, and their potential effects on shared decision-making, in second-opinion consultations.

Methods-Theme-oriented discourse analysis of 20 second-opinion consultations with subspecialist hematologist-oncologists.

Results-Physicians frequently "broadcasted" information about the disease, treatment options, relevant research, and prognostic information in extended, often-uninterrupted monologues. Their communicative styles had one of two implications: conveying options without offering specific recommendations, or recommending one without incorporating patients' goals and values into the decision. Some physicians, however, used techniques that encouraged patient participation.

Conclusions-Broadcasting may be a suboptimal method of conveying complex treatment information in order to support shared decision-making. Interventions could teach techniques that encourage patient participation.

Practice Implications-Techniques such as open-ended questions, affirmations of patients' expressions, and pauses to check for patient understanding can mitigate the effects of broadcasting and could be used to promote shared decision-making in information-dense subspecialist consultations.

\footnotetext{
(c) 2013 Elsevier Ireland Ltd. All rights reserved.

Corresponding Author at: Karan R. Chhabra, Rutgers Robert Wood Johnson Medical School, 675 Hoes Lane West, Piscataway, NJ 08854 USA, krchhabra@gmail.com, Phone: 201-218-5831, Fax: 732-235-5078.

Publisher's Disclaimer: This is a PDF file of an unedited manuscript that has been accepted for publication. As a service to our customers we are providing this early version of the manuscript. The manuscript will undergo copyediting, typesetting, and review of the resulting proof before it is published in its final citable form. Please note that during the production process errors may be discovered which could affect the content, and all legal disclaimers that apply to the journal pertain.
} 


\section{Keywords}

US; Physician-patient communication; Oncology consultations; Information delivery; Patient participation; Shared decision-making; Physician-patient relationships; Second opinions

\section{Introduction}

In the face of complex disease, physicians and patients struggle to make the "best" treatment decisions; that is, decisions most consistent with the patient's goals for care. This is particularly true for patients with hematological malignancies, many of whom are considering hematopoietic cell transplantation (HCT). These transplantations have wide variations in intensity; however, all involve a substantial amount of risk and invasiveness without the guarantee of a cure. Decisions on HCT, like many in the subspecialist setting, are highly sensitive to patient preferences [1]. Yet communication in subspecialist encounters remains relatively understudied. What is known is that although cancer patients vary in the level they want to be involved in the decision-making process, many do want to be involved [2]. Additionally, physicians and patients can experience conflict over treatment decisions [3]. Given the complexity of shared decision-making in these conversations, knowing how they occur could inform interventions aimed at improving them. However, little is known about the actual interactional dynamics of these subspecialist consultations. Thus, in this study, we sought to explore practices in subspecialist communication that may influence shared decision-making by examining encounters between patients with hematological malignancies and subspecialist hematologists.

\section{Methods}

\subsection{Data collection}

The physician-patient encounter transcripts in this analysis came from HEMA-COMM, a study of audio-recorded consultations between 236 patients and 40 hematologists at the Dana-Farber Cancer Institute (Boston, MA) and Fred Hutchinson Cancer Research Center (Seattle, WA) between 2003-2007. Their median duration was approximately 69 minutes [4]. The study was approved by the institutional review boards of both participating hospitals.

From this larger sample, 20 patients were purposively selected for further analysis (Table 1). They were chosen to reflect a diverse set of cancers, age ranges, and estimated prognoses, as well as relative balance in race and education. Fifteen physicians were represented in this sample. This manuscript reports on a qualitative analysis of the 20 audio-recorded consultation visits from this sample.

\subsection{Data analysis}

We used theme-oriented discourse analysis methods [5-7] to study how physicians' language choices affect the potential for shared decision-making. Unlike other approaches that only allow consideration of what is spoken, discourse analysis emphasizes prior ethnographic knowledge of the context as a whole [6]. Because the parties in a subspecialty consultation carry a substantial set of expectations and assumptions, we believed such a methodology was necessary.

We read each consultation transcript in close detail, first with an "unmotivated," inductive approach. As patterns emerged, we re-read each consultation transcript and annotated examples of each pattern, along with markers of power or control, such as turn-taking, question-taking, and topic control [7] as well as patients' expressions of emotion and 
treatment preference. Consultations with similar physician-patient relationships were re-read side-by-side, to assess patients' responses to certain physician behaviors and to isolate common linguistic features. Next, we compared our annotations of each consultation with the patients' reactions to them as articulated in their qualitative interviews.

This analysis differs from others based on the HEMA-COMM dataset [4, 8, 9]. A 2009 paper [4] qualitatively analyzed patients' reactions to their consultations based on separate interviews conducted with each patient. That paper focused on patients' reactions to their physicians' communication style but did not simultaneously assess the physician's communication style. A 2011 paper identified demographic predictors of advance care planning among patients with hematologic malignancies, but did not address communication in their consultations [8]. A 2012 paper [9] "counted" the frequency of certain recommended communication practices, and used multiple regression models to identify predictors of those practices. By focusing on "counts," however, it did not elaborate on the language used in each consultation. The present analysis, by contrast, deals explicitly with the language used by subspecialist physicians in each encounter to describe in detail the communicative behaviors of physicians and their immediate effects within the consultation.

\section{Results}

\section{1 Broadcasting}

The most ubiquitous finding was a pattern of lengthy physician monologues on disease mechanisms and history, treatment options, or prognostic information. We termed this pattern "broadcasting." A representative excerpt of a "broadcast" can be found in Table 2.

The most striking feature of the broadcast is its length: physicians occasionally spoke uninterrupted for ten minutes or longer, leaving very little time for patients to process information or ask questions before moving on to new topics. For example, throughout the excerpt in Table 2, the physician does not stop to allow the patient to speak. He outlines four different treatment options, but does not pause to ask the patient if she understood each of them. Throughout the dataset, there was some variation in how often physicians stopped and allowed patients to participate and in the length of the broadcast. Out of the 20 consultations, $17(85 \%)$ had an uninterrupted physician monologue at least 20 lines in length (the broadcast in Table 2 is 28 lines, each about 17 words), 10 (50\%) had one lasting at least 30 lines, and $6(30 \%)$ had one lasting at least 40 lines. Continuers or minimal utterances ("right," "mhm," etc.) were not interpreted as terminating the broadcast.

However, duration of uninterrupted speech is not the only defining feature of a broadcast. Intended topic control is also characteristic. Physicians did stop for interruptions, but often returned to the broadcast immediately after responding to the patient. Interruptions (by definition) were not invited by the physician. Once interruptions were answered, topic control remained with the physician.

In the Table 2 excerpt, the physician outlines treatment options in the order that they were developed. Apart from HCT, the physician says that the standard of care for chronic myelogenous leukemia progressed from hydroxyurea, to interferon, to Gleevec, and then explained how Gleevec was discovered in some detail. This "historical" format appeared frequently in our dataset.

Less common was this physician's act of individualizing each treatment option in terms of its appropriateness for the patient. Unlike many studied, this physician articulated his rationale for recommending against bone marrow transplantation, hydroxyurea, and interferon based on the unique characteristics of his patient. 


\section{2 "Deferential" language}

Unlike the physician in Table 2, many physicians did not evaluate each treatment on behalf of the patient. Instead, they used language that minimized their role in the patient's decision and deferred to the patient's autonomy. In this example, a physician is discussing the choice between Gleevec and HCT:

Physician: There's some patients who hear about the Gleevec and hear about the transplant stuff and say you know, I'm not going to do the transplant until I have to in the extreme. But there are actually some people who say I'm not going to...

This physician emphasizes that "some patients" choose each approach, presumably to illustrate that either would be a good decision. By referring to hypothetical patients, however, the physician does not apply his knowledge to the particulars of this patient's case or guide the patient with a specific recommendation.

Another related pattern was physicians' use of the second person "you" (note underlined language):

Physician: or if you really sort of feel like you didn't want to be in a clinical trial, we are ok with that if you don't want to be in the clinical trial. ... if you are particular interested in pursuing the [inaudible] mini-transplant then you need to figure out if your brother matches you. Kind of you have to decide I think when you leave here if that is a viable option that you want to pursue and in which case then our next step would be get your brother's blood and your blood and type you two.

By saying "you need to figure out" the treatment course, this physician, like several others, repeatedly emphasizes the patient's agency relative to his own. He uses the "we" form when he says "our next step," but this step is contingent on the patient ("you") deciding on a minitransplant. Passage 2 shows a significantly different stance from that of Table 2, in which the physician says "I'll probably decide on a bone marrow transplant," implying that the decision is his own rather than the patient's.

\section{3 "Directive" Language}

In Table 2 and in other consultations, physicians communicated in ways that implied that they are conveying the right decision-the opposite of "deferential" language.

Physician: Some of the new treatments for myeloma are, um, combining Decadron, which I just mentioned to you, with thalidomide, orally, which is very effective and will get rid of a lot of protein. Or, the other one is called Velcade... So, the only thing that I would mention to you is that the Velcade and the thalidomide, although I think they are terrific, ... the Decadron does not cause neuropathy. OK, the thalidomide and the Velcade both cause neuropathy. So for someone who has a bad neuropathy ... I would probably vote with starting first with just Decadron alone ... Let's say four days in a row, maybe, why don't we do the 4 days on 4 days off, 4 days on 4 days off, 4 days on 4 days off, 12 days a month. Cause we, for a couple of months, that's pretty aggressive. But that's really trying to get you out of trouble, okay?

Patient: Yes, cause I gotta get out of trouble.

Here, the physician explains that Decadron, Velcade, and/or thalidomide are all good treatments for myeloma, but given the patient's neuropathy, he would favor an aggressive treatment of Decadron alone. Note the contrast between his language ("I would vote") and that of Passage 2 ("you have to decide"). He places more emphasis on his agency than the 
patient's. Without pausing after explaining the risks of Velcade and thalidomide, he immediately begins to outline an aggressive regimen of Decadron alone. And when he cedes the floor to the patient, it is not for the patient to ask about alternative treatment options.

Rather, his question ("that's really trying to get you out of trouble, okay?") serves to confirm that the patient understands his rationale before explaining further details of his Decadron treatment plan.

The excerpt in Table 2 exhibits similar features. The physician does not turn the conversation to the patient while other treatments (bone marrow transplantation, hydroxyurea, interferon) are still options. Rather, he delves straight into the results he has observed with Gleevec. He does so without allowing the patient to ask more about the alternative treatments. Additionally, as discussed in Section 3.2, his pronoun choice is significant: "I'll probably decide on doing a bone marrow transplant" rather than "you could," or something similar.

\section{4 "Inviting" Language}

Several physician communication behaviors appeared to encourage patient participation in the consultation. For example, this exchange has a markedly different pattern from the "broadcast" in Table 2:

Physician: I'll be very happy to help you with that. Ok. Now, um, [Patient], in terms of treatment, what have you been told so far about what would be the next steps?

Patient: Well, I was told that most probably it will be chemotherapy of some kind, that there are several different um drugs that can be used.

\section{Physician: Right.}

Patient: That the major differences between them would probably be the length of remission that we might have.

\section{Physician: Yes.}

Rather than describing the next steps himself, this physician allows the patient to tell him what she knows with an open-ended question. In addition, rather than cutting the patient off, he uses affirmations like "right" and "yes" to encourage her to continue her response. This may limit the amount of information the physician later needs to deliver.

Another excerpt illustrates yet another way that some physicians encouraged their patients to participate in the conversation:

Physician: So it works both ways, because the incoming donor cells, so we want to get the donor cells to engraft ... to be accepted, into your body and replace your immune system, so as it's doing that we don't want it to attack your body too strongly.

\section{Patient: Right}

Physician: And if the host cells, if your body kicks out the incoming donor cells, then you're rejecting the graft, but if the donor cells attack your body too strongly, that is called graft versus host disease.

Patient: Oh I've heard of that

Physician: The donor cells, the graft cells, versus you the host.

Patient: Right, that's the point that that happens 
Physician: Yeah... after the transplant has happened, engrafted, after the donor cells take, and are engrafted.

Patient: Right.

This physician appears to encourage a response, however brief, after each item of information-implicitly inviting the patient to confirm that her understanding. This may be the result of pausing, altering intonation, or some other combination of interactional cues. From this excerpt, one can see that the physician need not ask the patient to confirm her understanding after each sentence-she does so on her own, presumably invited by some aspect of the physician's speech. The patient also does not use those cues to take over the conversation; the physician continues his explanation without veering off topic. This style of encouraged participation differs significantly from the "broadcast" where the patient would have to interrupt to show understanding or ask questions.

\section{Discussion and Conclusion}

\subsection{Discussion}

This analysis revealed how certain subspecialist communicative behaviors may influence the potential for shared decision-making between the patient and physician. The first and most salient feature was most physicians' tendency to "broadcast" information in extended monologues. These monologues were characterized by remarkable length, unilateral topic control, and patterns of information delivery that varied little from patient to patient. The research team coined the term "broadcasting" to emphasize its unilateral, uniform naturerelying little on patient feedback and appearing rehearsed rather than individualized. Though communication styles varied, broadcasting was virtually ubiquitous. The purpose of these subspecialist consultations was, of course, to provide patients with information and treatment options. So broadcasting may have been a well-intentioned way to convey as much information as possible in a finite time period.

However, 40-80\% of medical information is forgotten immediately after a consultation [10]. Mentioning certain information in the course of a broadcast does not ensure that the patient will understand or retain it. Additionally, an increased proportion of physician speech (relative to the family's) has been linked to decreased family satisfaction in the critical care setting [11]. In many of our cases, the sheer amount of information delivered visibly increased patients' anxiety levels as well, causing overt statements of fear, confusion, or distress.

In addition, the typical organization of these broadcasts may not be the optimal way to present choices to a patient. Our data showed a tendency for physicians to describe treatment options all at once, often in a "historical" sequence mirroring the order in which each option was developed. While it may be natural for a physician-researcher who has seen each option develop, it has little relation to the relative risks and rewards of each option. An approach that discusses treatment options sequentially, according to their risk/reward ratio, has been proposed to better explain the tradeoffs of each option [12].

Broadcasts had no specific position in the sequence of the consultation, and were used for a variety of purposes. They typically dealt with treatment options in some way, in keeping with the goals of the subspecialist consultation, but the specific content varied. The "historical" approach mentioned before was common, but some physicians used broadcasts to explain disease biology, propose a treatment course, or to share the prognosis associated with each treatment option. At the close of the broadcast, the consultation continued in briefer turns with a larger role for patient input. Physicians and patients found agreement on intermediate steps, such as human lymphocyte antigen (HLA) testing or a follow-up 
conversation with the referring oncologist. However, in the majority of consultations, a definitive decision to pursue treatment with the subspecialist was not made.

As shown in Section 3.4, certain practices broke up the rhythm of broadcasting and "invited" patients to participate more. Open-ended questions assessed patients' prior knowledge to focus information delivery. Affirmations and periodic pauses also encouraged patients to enter the conversation. These behaviors are particularly important when facing patients less confident in their ability to communicate with the physician [13]. Of course, physicians "invite" patient speech routinely as they obtain the patient's history. However, such invitations were considered relevant to this study because they do not enhance the patient's role in decision-making; history-taking is part of even the most physiciandominated conversations. In this study, we highlighted physician practices that allowed the patient to participate in information delivery and decision-making.

We observed two patterns that appeared to reflect the physician's desired role in decisionmaking: deferential and directive language. These types of speech were not restricted to broadcasts, occurring even in rapid exchanges when treatment options were being discussed. However, if one pattern predominated in a broadcast, it typically characterized the remainder of the consultation as well. Deferential strategies helped physicians lay treatment options out neutrally, but physician neutrality appears inadequate as treatment options multiply and the complexity of tradeoffs increases [2, 14, 15] [15] — both of which are particularly true in subspecialty consultations.

By contrast, "directive" language allowed physicians to assert their opinions in the decisionmaking process. It was characterized by use of the first person ("I'll vote for"), and often an explicit mention of the patient characteristics that led to that recommendation; together, these suggest that the physician's recommendation is the only right choice. As in Passage 3, physicians occasionally issued strong recommendations ("Decadron alone") eventually followed by language deferring to the patient ("that's trying to get you out of trouble, okay?"). The question may serve to hedge the directive recommendation, but its format still implied that the recommendation was the best option. Such hedges did not appear to change the generally directive nature of the consultation as a whole. That is, though a physician may use deferential language to hedge directive comments, the overall tone of the consultation remained directive.

Of course, it is safe to assume that physicians have their patients' best interests at heart when they make a recommendation. And in many cases, the treatment choices may be obvious. However, according to past research, directive strategies make it increasingly difficult for patients to disagree without threatening the physician's authority [16-18]. Consider how in Passage 3, the patient does not articulate that she has chosen Decadron over the other options, but merely that she assents to the physician's reasoning ("Yes, cause I gotta get out of trouble"). Past research on similar exchanges has concluded that patients often do not understand they have a choice to make. Instead, such responses reflect assent rather than consent, which is not equivalent to informed choice [19].

The difference between assent and informed consent is subtle, but critical. Patients' fear of appearing "difficult" makes them significantly less likely to challenge a physician's recommendations and achieve shared decision-making [20]. This is not to say that physicians' recommendations are inherently coercive or problematic-patients often want personalized recommendations from their physicians [2, 4, 14]. But these findings underscore two needs: first, for physicians to understand their patients' decision-making preferences at the outset of a consultation, and second, for them to be acutely sensitive to the fact that their patients may be reluctant to challenge their authority. Since directive language 
is likely to exacerbate such reluctance, physicians seeking to encourage patient participation should use such language with care. Conversely, if patients reveal that they would prefer the physician to make an explicit treatment recommendation, physicians should monitor their use of deferential language.

Our study had several limitations. First, the consultations came only from two sites and 15 physicians. The observations may have been specific to those sources. Second, we lacked an objective method of assessing patient reactions to communication behaviors in the moment. That is, we were not able to judge patients' satisfaction, distress, or understanding of information in real-time. Instead, we relied on patients' verbal responses to their physicians' communicative behaviors. Third, it is possible that physicians' communicative behaviors depended entirely on what was available - that, for example, physicians only took directive approaches when there was just one suitable option, and always took distancing approaches when there were multiple. However, the fact that physicians mentioned multiple treatment approaches even when using directive language suggests that this was not the case.

\subsection{Conclusions}

We observed a variety of communication styles, but many conversations shared the use of lengthy physician "broadcasts" to explain disease mechanisms, treatment options, or prognostic information. Given past research on information retention, risk communication, and patient satisfaction [10-12] as well as our observations of patient responses, broadcasting may be a suboptimal way of conveying complex treatment information in the subspecialist encounter. However, we documented several communication behaviors that appeared to promote patient participation and could be used by physicians to prompt their patients to articulate themselves. We also captured examples of language that encourages patients to make decisions independently, as well as language that supports a more dominant physician role in decision-making. We argue that neither is a priori preferable, but rather should be matched to patients' preferences and characteristics as well as the physician's communicative aims. This paper took an exploratory, inductive approach to identifying themes in subspecialist communication. Future studies should examine these themes explicitly, with patient-centered outcomes (information comprehension, satisfaction, distress, etc.) and objective measures of shared decision-making as endpoints.

\subsection{Practice Implications}

Our results offer typical examples of the various communication behaviors used by subspecialists in first-time consultations. They support past research demonstrating the heterogeneity of physicians' orientations toward shared decision-making [14, 21], but more importantly, they show how styles manifest in actual encounters. Broadcasting may help physicians establish credibility and give a general overview of relevant information, both important objectives of an initial visit, but it may be an ineffective means of patient education $[4,10-12]$. Inviting behaviors are ways to facilitate patient participation in the encounter as well as to explore patients' values and goals for treatment. Deferential and directive speech have both strengths and weaknesses, but styles should be chosen carefully, with a regard for the patient's preference in decision-making and the presence (or absence) of equipoise $[15,21,22]$.

Since these examples bridge the gap between archetypes of physician style and real-life talk, they may be valuable as heuristics for clinicians and researchers assessing communication style. Clinicians may be able to identify commonalities between their communication behaviors and those outlined in this paper. Finally, though subspecialist consultations are unique in many ways, information delivery constitutes a great share of physician-patient communication. Because the themes of this paper revolve around communicating treatment 
options, these findings could extend to any medical context in which preference-sensitive decision-making plays an important role.

I confirm all patient/personal identifiers have been removed or disguised so the patient/ person(s) described are not identifiable and cannot be identified through the details of the story.

\section{Acknowledgments}

This paper was supported by National Cancer Institute grant CA 098486.

\section{References}

1. Patenaude A, Rappeport J, Smith B. The physician's influence on informed consent for bone marrow transplantation. Theor Med Bioeth. 1986; 7:165-79.

2. Gaston CM, Mitchell G. Information giving and decision-making in patients with advanced cancer: A systematic review. Soc Sci Med. 2005; 61:2252-64. [PubMed: 15922501]

3. Lee H, Lee YC, Shin S, Park JC, Shin SK, Lee SK, Noh SH. Participation and conflict in the decision-making process for endoscopic resection or surgical gastrectomy for early gastric cancer. J Surg Oncol. 2012; 106:101-6. [PubMed: 22258736]

4. Goldman RE, Sullivan A, Back AL, Alexander SC, Matsuyama RK, Lee SJ. Patients' reflections on communication in the second-opinion hematology-oncology consultation. Patient Educ Couns. 2009; 76:44-50. [PubMed: 19135824]

5. Cameron, D. Working with spoken discourse. Sage Publications Limited; 2001.

6. Roberts C, Sarangi S. Theme-oriented discourse analysis of medical encounters. Med Educ. 2005; 39:632-40. [PubMed: 15910440]

7. Ainsworth-Vaughn, N. Claiming Power in Doctor-Patient Talk. New York: Oxford University Press; 1998.

8. Loberiza FR Jr, Swore-Fletcher BA, Block SD, Back AL, Goldman RE, Tulsky JA, Lee SJ. Coping styles, health status and advance care planning in patients with hematologic malignancies. Leuk Lymphoma. 2011; 52:2342-8. Epub 2011 Aug 18. 10.3109/10428194.2011.601474 [PubMed: 21851220]

9. Alexander SC, Sullivan AM, Back AL, Tulsky JA, Goldman RE, Block SD, Stewart SK, WilsonGenderson M, Lee SJ. Information giving and receiving in hematological malignancy consultations. Psycho-Oncol. 2012; 21:297-306.

10. McGuire LC. Remembering what the doctor said: organization and adults' memory for medical information. Exp Aging Res. 1996; 22:403-28. [PubMed: 8968711]

11. McDonagh JR, Elliott TB, Engelberg RA, Treece PD, Shannon SE, Rubenfeld GD, Patrick DL, Curtis JR. Family satisfaction with family conferences about end-of-life care in the intensive care unit: Increased proportion of family speech is associated with increased satisfaction*. Crit Care Med. 2004; 32:1484-8. [PubMed: 15241092]

12. Zikmund-Fisher BJ, Angott AM, Ubel PA. The benefits of discussing adjuvant therapies one at a time instead of all at once. Breast cancer research and treatment. :1-9.

13. Zandbelt LC, Smets EM, Oort FJ, Godfried MH, de Haes HC. Medical specialists' patient-centered communication and patient-reported outcomes. Medical care. 2007; 45:330-9. [PubMed: 17496717]

14. Adams R, Price K, Tucker G, Nguyen A-M, Wilson D. The doctor and the patient - How is a clinical encounter perceived? Patient Educ Couns. 2012; 86:127-33. [PubMed: 21890301]

15. Woolf S, Chan E, Harris R, Sheridan S, Braddock C, Kaplan R, Krist A, O'Connor A, Tunis S. Promoting informed choice: transforming health care to dispense knowledge for decision making. Ann Int Med. 2005; 143:293. [PubMed: 16103473]

16. Costello BA, Roberts F. Medical recommendations as joint social practice. Health Commun. 2001; 13:241-60. [PubMed: 11550850] 
17. Hudak PL, Clark SJ, Raymond G. How surgeons design treatment recommendations in orthopaedic surgery. Soc Sci Med. 2011; 73:1028-36. [PubMed: 21855192]

18. Quirk A, Chaplin R, Lelliott P, Seale C. How pressure is applied in shared decisions about antipsychotic medication: a conversation analytic study of psychiatric outpatient consultations. Sociol Health Ill. 2012; 34:95-113. Epub 2011 Aug 3. 10.1111/j.467-9566.2011.01363.x

19. Pilnick A. 'It's something for you both to think about': choice and decision making in nuchal translucency screening for Down's syndrome. Sociol Health Ill. 2008; 30:511-30.

20. Frosch DL, May SG, Rendle KAS, Tietbohl C, Elwyn G. Authoritarian Physicians And Patients' Fear Of Being Labeled 'Difficult' Among Key Obstacles To Shared Decision Making. Health Aff. 2012; 31:1030-8.

21. Edwards, A.; Elwyn, G. Shared decision-making in health care: Achieving evidence-based patient choice. Oxford University Press; USA: 2009.

22. Elwyn G, Edwards A, Kinnersley P, Grol R. Shared decision making and the concept of equipoise: the competences of involving patients in healthcare choices. Brit J Gen Pract. 2000; 50:892.

[PubMed: 11141876] 


\section{Research Highlights}

- Explores practices in subspecialist physicians' communication styles, with regard to shared decision-making

- Hematologists delivered information in lengthy "broadcasts," which may be suboptimal for sharing complex decision-making

- "Deferential" language emphasized patient autonomy and minimized the physician's role in the decision

- "Directive" language focused on the physician's recommendation, excluding alternative treatment options

- Certain communicative behaviors encourage patient participation and may promote shared decision-making 
Table 1

Participant Characteristics

\begin{tabular}{|c|c|c|c|}
\hline Patients [n=20] & $N(\%)$ & Physicians [ $n=15$ ] & $\mathbf{N}(\%)$ \\
\hline Gender & & Gender & \\
\hline Male & $8(40 \%)$ & Male & $13(85 \%)$ \\
\hline Female & $12(60 \%)$ & Female & $2(15 \%)$ \\
\hline Disease & & Age & \\
\hline Acute leukemia & $6(30 \%)$ & $30-39$ & $3(20 \%)$ \\
\hline Chronic leukemia & $3(15 \%)$ & $40-49$ & $5(33 \%)$ \\
\hline Multiple myeloma & $6(30 \%)$ & $50-59$ & $6(40 \%)$ \\
\hline Lymphoma & $2(10 \%)$ & $60-69$ & $1(7 \%)$ \\
\hline Myelodysplastic syndrome & $2(10 \%)$ & & \\
\hline Aplastic anemia & $1(5 \%)$ & & \\
\hline \multicolumn{4}{|l|}{ Age } \\
\hline $30-39$ & $6(30 \%)$ & & \\
\hline $40-49$ & $3(15 \%)$ & & \\
\hline $50-59$ & $6(30 \%)$ & & \\
\hline $60-69$ & $4(20 \%)$ & & \\
\hline $70-79$ & $1(5 \%)$ & & \\
\hline \multicolumn{4}{|l|}{ Race } \\
\hline Black & $5(25 \%)$ & & \\
\hline White & $12(60 \%)$ & & \\
\hline American Indian/Asian/Pacific Islander & $3(15 \%)$ & & \\
\hline \multicolumn{4}{|l|}{ Education } \\
\hline Less than college & $2(10 \%)$ & & \\
\hline Some college/college degree & $12(60 \%)$ & & \\
\hline Postgraduate degree & $6(30 \%)$ & & \\
\hline
\end{tabular}


Table 2

\section{Representative Excerpt of a Physician "Broadcast"}

\section{Physician:}

[If] a 25 year old comes in, with your condition, the same CML in stable phase and has a sibling that matches, you know, I'll probably decide on doing a bone marrow transplant. Knowing there is a risk of this transplant, but if you do well with the transplant, it's a good chance that you're cured. However, for people who are older and who have medical conditions, you know, for example, in your case the colon cancer and other issues, um, those kind of transplants might be a bit too risky. In a person whose age is over 40 or 50 , the risk of dying from the transplant itself is fairly high and therefore we have not been pushing for patients, at this age, to all get transplants.

So what's the alternative to transplantation, is the next question. So, in the past, there hadn't been any very good treatments for this disease. People have used a drug called Hydrea to control the counts, Hydroxyurea, it's a pill you take once a day. That controls your white blood cell counts but it does not delay the progression of the disease and does not change survival. The only drug in the past that has impacted on survival is a drug called interferon. ... The problem with interferon is that it is a terrible drug. People get very depressed on it, people get lots of flu like symptoms, so, you know, based on what you are telling me now, I think interferon would be a very bad drug for you, just because of the depression issues, the fibromyalgia issues. Furthermore interferon is not all that effective. It maybe about $15 \%$ will achieve what they call a cytogenetic remission; you see that the chromosome goes away, the Philadelphia chromosome...

Well the exciting thing is then, there's this drug called Gleevec. It's obviously a recent development. Gleevec has been approved only a couple of years ago, 3 or 4 years ago. And the way Gleevec works, is that, Gleevec is actually the first drug, what we call a rationally designed drug. ... As I told you, this disease, it's the hallmark of the disease, is this translocation, where you have this break between chromosome 9 and chromosome 22. It makes this new Gene called the BCR-ABL gene. Well, since we've been able to clone this gene, they actually make this thing in the laboratory, you can actually test things that can block it. Well one of the researchers ... was interested in seeing if he could find chemicals that specifically block this gene. ... And after going through an exhaustive search, they've isolate one, in particular, that seems to be very effective in blocking the action of this gene. ... And so, you know, basically, it's very basically a design drug. 